\title{
Assessment of Force decay of different orthodontic power chains without pre-stretching
}

\author{
Ahmed Maher Fouda ${ }^{1}$
}

\section{ABSTRACT:}

Objective: The purpose of this study was to determine the force decay value of four different types of power chains used in orthodontic treatment. MaterialsandMethods: A sample of 20 specimens, which was divided into five piece taken from each type of the four power chains, each piece, contains six rings. The rings were placed on steel pins embedded in acrylic sheets and poured in hard stone blocks. The force of the elastomeric chains was recorded in dry state and compared to data after immersion in artificial saliva at 37 degree in bacterial incubator at time interval of 1 hour, 1 day, 1 week, 3 weeks. Results: Significant difference was found in percentage of reduction in force between the four types of the power chains in dry field and after immersion in artificial saliva. After 3 weeks testing Morelli power chains had $41.8 \%$ reduction in force, Ultimate power chains scored $36.9 \%$ reduction in force, Dentsply power chains scored 30.8\% reduction in force and U[tra- chains scored $27.2 \%$ reduction in force. Conclusion: All types of power chains showed force decay with different values after 3 weeks of testing. Choose the appropriate force value for tooth movement play important role success of orthodontic treatment. Keywords: orthodontic treatment, tooth movement, force decay, Elastomeric chain.

\section{INTRODUCTION}

Most of the elastics used in orthodontics are made of polyurethane [synthetic elastics] ${ }^{1}$ The word elastomer is used for any substance including rubber that stretches easily to several times its length and returns to its original shape. The orthodontic Power chains or elastics are widely used element in orthodontic treatment since many years. They can be easily applied on the orthodontic brackets to apply force for retraction or rotation and they are hygienic.So elastomeric power chains are biocompatible and suitable for clinical application ${ }^{2}$. The main disadvantages are force degeneration and color change due to food or drink in the mouth. Elastomeric chains provide force used to move teeth, but this force is not constant during orthodontic treatment ${ }^{3}$. In a previous studies, it was concluded that extreme force decay occur in the first hour ${ }^{4}$. Force decay is very rapid in the first 24 hours ranges from 50 to $70 \%$ of the initial force. In other study, it was showed that force levels of the chains from different manufacturers vary widely, some chains have excessive initial force than other ${ }^{5}$.

Many authors recommended prestretching the orthodontic power chains

${ }^{1}$ Lecturer of Orthodontics, Orthodontic Department, Faculty of Dentistry, Mansoura University 
before use to assure more stable force levels during orthodontic treatment ${ }^{3}$. Prestretching was evidence only in first hour and after 4 weeks similar remaining of forces were found between the pre-stretch and the control group $^{6}$. There was a report that force decay occurs rapidly in both in air and in artificial saliva and the decay was higher in the latter ${ }^{7}$. They reported also that the more acidic $\mathrm{pH}$, the greater the force decay occurs. There are many factors in the oral cavity that affect the behavior of the power chain, such as patient dental hygiene, temperature, microbial action and $\mathrm{pH}$ level ${ }^{8}$.

There are variety of orthodontic companies that offer the power chain with different values. The aim of this study was to determine the force decay value of four different types of elastic power chains without pre-stretching.

\section{MATERIALS AND METHODS}

A sample of 20 pieces of power chain from four different companies were randomly chosen from the market in this study. Five pieces taken from each type of the four power chains, each piece contains six rings. The power chains that were used in the study are: Ultimate power chain (short silver, USA); Dentsply (clear open, USA); Morelli (small, Brazil) and Ultra chain (short, china) [fig.1]. Four blocks were made of acrylic plate with steel pins that carry the elastomeric modules [fig.2]. The blocks were poured with hard stone to reinforce the pins. The distance between the pins was $26 \mathrm{~mm}$ (approximately the distance between the upper first molar and the upper canine). Each module of the four types of the power chain was cut with excess rings for ease of application and the modules were marked by red marker for ease in measuring. Each block was coded by a sample and wrote on it the type of power chains that carries. In the dry state, the elastomeric force was measured after adjusting on the steel pins without pre-stretching at intervals: 1 hour, 1 day, 1 week and 1 month. Then the four blocks were adjusted in metal plate containing artificial saliva. Modified fusayama artificial saliva with $\mathrm{pH}$ of 6 at $37^{\circ} \mathrm{c}$ was used. The artificial saliva consisted of $\mathrm{NaCL}(400 \mathrm{mg} / \mathrm{L})$, KCL (400mg/L), CaCL2.2H2O (795 mg/L), $\mathrm{NaH} 2 \mathrm{PO} 4 . \mathrm{H} 2 \mathrm{O}(690 \mathrm{mg} / \mathrm{L}), \mathrm{KSCN}$ (300 $\mathrm{mg} / \mathrm{L}), \mathrm{Na} 2 \mathrm{~S} .9 \mathrm{H} 2 \mathrm{O}$ (5 mg/L), and urea (1000 $\mathrm{mg} / \mathrm{L})^{[9]}$. The metal plate with the test group was stored in a bacterial incubator (JSR, JSGI 100-KOREA) at $37^{\circ} \mathrm{c}$. The elastomeric force was measured at intervals: 1 hour, 1 day, 1 week and 1 month after immersion in saliva. All the measurements were made by using digital force gauge (Extech,TAWAIN) in grams with special holder designed for this test. The distance between the hook of the digital force gauge and the hook in the base was equivalent to the distance between the steel pins $(26 \mathrm{~mm})$. The measurements of the elastomeric chains were recorded after transferred from the pins to the digital force gauge hook and the base hook by one minute on the stopwatch for accurate readings [Fig.3]. 


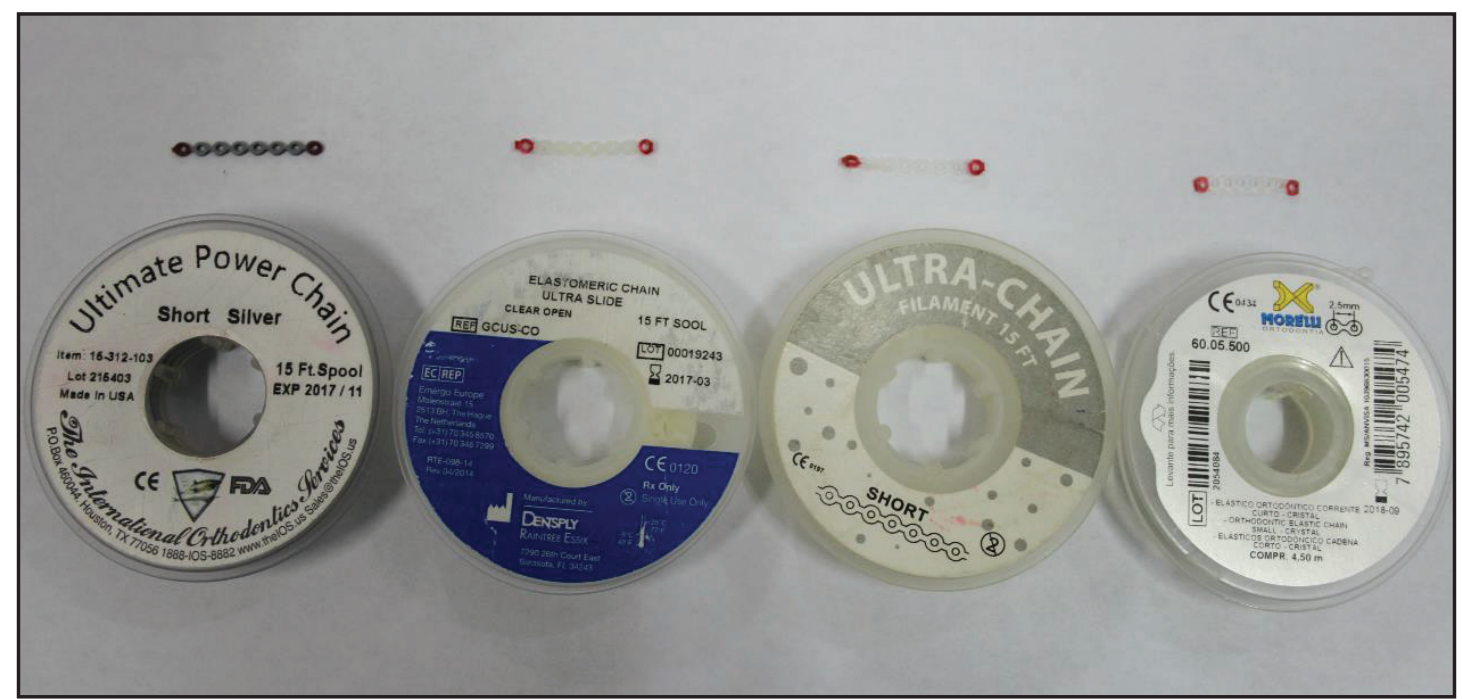

Fig (1): power chain samples.

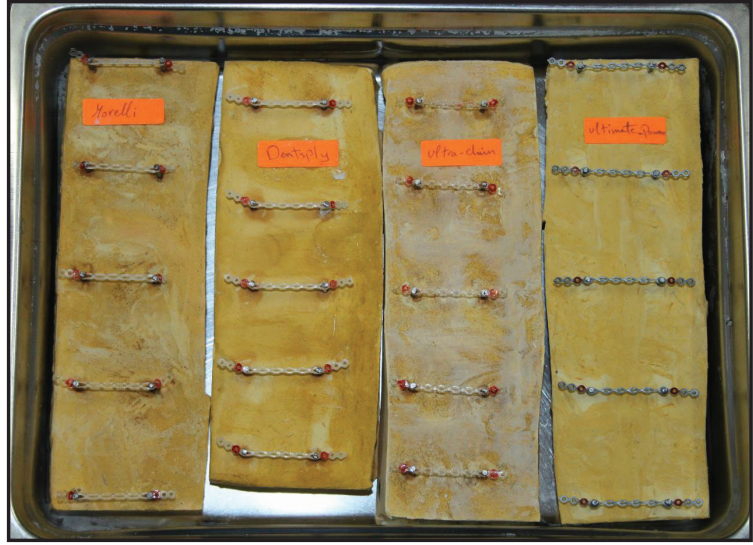

Fig (2): stone blocks with steel pins.

\section{Statistical analysis}

Data were fed to the computer and analyzed using IBM SPSS software package version 20.0 (Armonk, NY:IBM Corp). The kolmogrov-Smirnov test was done to verify the normality of distribution of variables. Student t-test was used for comparing between forces without and with saliva. Analysis of variance (ANOVA) test was used to compare between different timing and post-Hoc (Tucky) test for comparing between each pair. Significance of the obtained results was judged at the $5 \%$ level.

\section{Results}

Significant differences were found in percent-

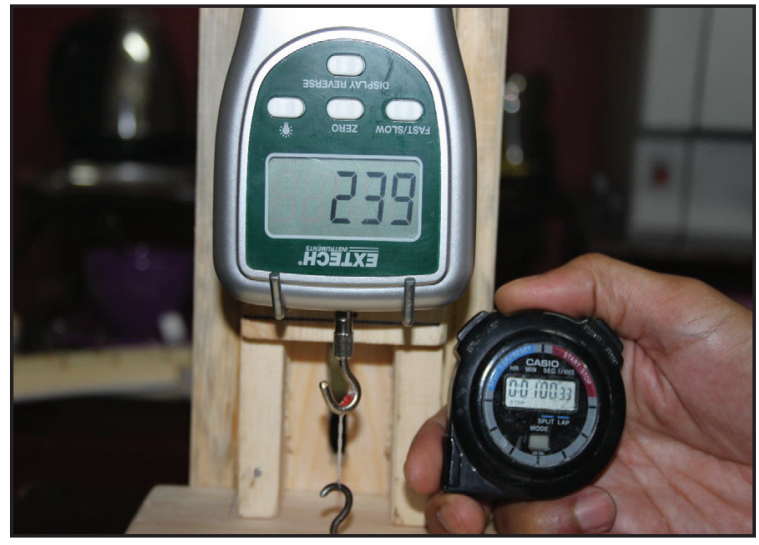

Fig (3): force calculation after 1 minute.

age of reduction in the force between the four types of power chains that immersed in saliva and with the samples not immersed in saliva [Table 1 and Graph 1].

Mean and standard deviation and percentage of reduction of the force were calculated for each type of elastic among 4 intervals (in the saliva and without saliva).

In all samples from the beginning of the test to the end of it, a significant force loss was seen in all the samples with different values. 


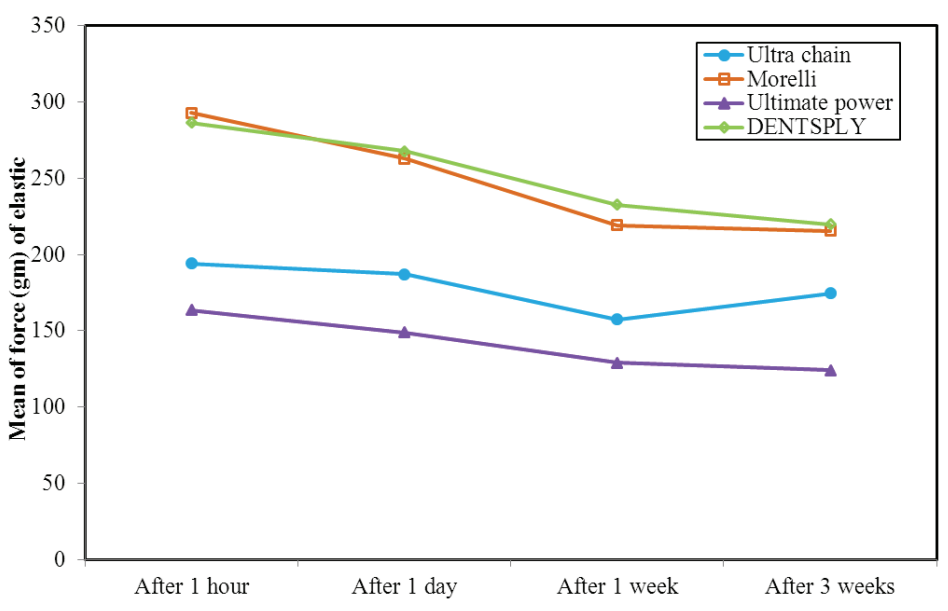

Time intervals

Table (1): Comparison between the two studied groups according to force (gm) of elastic sample

\begin{tabular}{|c|c|c|c|c|c|c|c|}
\hline \multirow{2}{*}{\multicolumn{2}{|c|}{$\begin{array}{c}\text { Force (gm) of Elastic } \\
\text { Sample }\end{array}$}} & \multicolumn{2}{|c|}{$\begin{array}{l}\text { Without saliva } \\
\quad(n=5)\end{array}$} & \multicolumn{2}{|c|}{$\begin{array}{l}\text { With saliva } \\
\quad(n=5)\end{array}$} & \multirow{2}{*}{$\begin{array}{c}\% \\
\text { reduction }\end{array}$} & \multirow[t]{2}{*}{$\mathbf{p}_{1}$} \\
\hline & & Mean & \pm SD. & Mean & \pm SD. & & \\
\hline \multirow{5}{*}{ 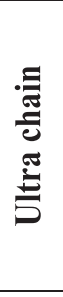 } & After 1 hour & 228.2 & 12.8 & 194.0 & 4.2 & 15.0 & $0.003^{*}$ \\
\hline & After 1 day & 232.4 & 5.94 & 187.2 & 10.4 & 19.4 & $<0.001^{*}$ \\
\hline & After 1 week & 223.2 & 9.73 & $157.4^{\#}$ & 21.6 & 29.5 & $<0.001^{*}$ \\
\hline & After 3 weeks & 239.8 & 8.01 & 174.6 & 14.2 & 27.2 & $<0.001^{*}$ \\
\hline & $\mathbf{p}_{2}$ & \multicolumn{2}{|c|}{0.076} & \multicolumn{2}{|c|}{$0.004^{*}$} & & \\
\hline \multirow{5}{*}{ 离 } & After 1 hour & 344.2 & 19.08 & 292.8 & 14.69 & 14.9 & $0.001^{*}$ \\
\hline & After 1 day & 349.8 & 12.77 & 263.0 & 22.73 & 24.8 & $<0.001^{*}$ \\
\hline & After 1 week & 345.6 & 7.37 & $219.2^{\#}$ & 24.24 & 36.6 & $<0.001^{*}$ \\
\hline & After 3 weeks & $370.4^{\#}$ & 8.93 & $215.4^{\#}$ & 18.77 & 41.8 & $<0.001^{*}$ \\
\hline & $\mathbf{p}_{2}$ & \multicolumn{2}{|c|}{$0.018^{*}$} & \multicolumn{2}{|c|}{$<0.001^{*}$} & & \\
\hline \multirow{5}{*}{ 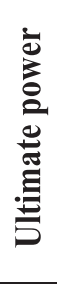 } & After 1 hour & 200.4 & 4.77 & 163.4 & 5.5 & 18.5 & $<0.001^{*}$ \\
\hline & After 1 day & 203.20 & 12.3 & 149.0 & 13.82 & 26.7 & $<0.001^{*}$ \\
\hline & After 1 week & 199.4 & 8.96 & $129.0^{\#}$ & 9.46 & 35.3 & $<0.001^{*}$ \\
\hline & After 3 weeks & 196.6 & 19.73 & $124.0^{\#}$ & 8.69 & 36.9 & $<0.001^{*}$ \\
\hline & $\mathbf{p}_{2}$ & \multicolumn{2}{|c|}{0.874} & \multicolumn{2}{|c|}{$<0.001^{*}$} & & \\
\hline \multirow{5}{*}{$\frac{\vec{Z}}{\sum_{0}^{2}}$} & After 1 hour & 325.8 & 9.93 & 286.4 & 10.81 & 12.1 & $<0.001^{*}$ \\
\hline & After 1 day & 315.2 & 6.76 & 267.8 & 12.46 & 15.0 & $<0.001^{*}$ \\
\hline & After 1 week & $303.6^{\#}$ & 7.50 & $232.6^{\#}$ & 11.55 & 23.4 & $<0.001^{*}$ \\
\hline & After 3 weeks & 317.8 & 13.05 & $219.8^{\#}$ & 19.98 & 30.8 & $<0.001^{*}$ \\
\hline & $\mathbf{p}_{2}$ & \multicolumn{2}{|c|}{$0.017^{*}$} & \multicolumn{2}{|c|}{$<0.001^{*}$} & & \\
\hline
\end{tabular}

1- $\mathrm{p}$ values for Student t-test for comparing between without and with saliva

2- $p$ values for ANOVA test Post Hoc Test (Tukey) for comparing between After 1 hour and each other period 3- Significant with After 1 hour

4- Statistically significant at $\mathrm{p} \leq 0.05$ 


\section{Discussion}

It is very important to know the manner of the elastic chain to achieve progress in orthodontic treatment. This will help to understand the retraction of canine as rate of canine retraction can be increased when force immediately apply after tooth extraction ${ }^{10}$. In a previous study, it was found that the amount of force loss occurred in the first 24 hours, and it was about half of the whole force loss in 4 weeks ${ }^{4}$. In the present study evaluation of the percentage of force decay occur in the elastic chain that immersed in artificial saliva at $37^{\circ} \mathrm{C}$ (to see the influence in mouth temperature and saliva). The pins in the acrylic plate were aligned with distance of $26 \mathrm{~mm}$ to simulate canine retraction distance in case of extraction of first premolar. A six model of each type of the elastic chain was connected between two parallel steel pins for standardization of force. It was found in this study that force decay percentage increase after immerse of the power chains in artificial saliva for 3 weeks (which simulate situation in case of orthodontic treatment in clinic).

The percentage of reduction of force of the four elastic chains during different intervals of test after immersion in artificial saliva was evidences; as after 1 hour the Ultimate power chains showed higher percentage of reduction in force with $18.5 \%$ while the Ultra-chains scored $15 \%$ loss followed by Morelli power chains of $14.9 \%$ loss and then Dentsply power chain with $12.1 \%$ loss.

After 1 day the Ultimate power chains also showed higher percentage of reduction in force with $26.7 \%$ loss followed by Morelli power chains with $24.8 \%$ loss, then Ultra-chains with $19.4 \%$ loss and finally Dentsply power chains with $15 \%$ loss.

After 1 week Morelli power chains showed higher percentage of reduction in force with 36.6
$\%$ loss followed by Ultimate power chains with $35.3 \%$ loss, then Ultra-chains with $29.5 \%$ loss and finally Dentsply power chains with $23.4 \%$ loss.

After 3 weeks Morelli power chains showed higher percentage of reduction in force with $41.8 \%$ loss followed by Ultimate power chains with $36.9 \%$ loss, then Dentsply power chains with $30.8 \%$ loss and finally Ultra-chains with $27.2 \%$ loss. These results weren't in agreement with previous findings ${ }^{11-12}$

There was a decline in the amount of force in grams of the four elastic chains during different intervals of test. In dry field, Morelli power chain showed higher range of force in grams range from 344.2 to 370 grams, While Dentsply power chains came the second with force ranged from 303.6 to 325.8 grams. Ultra-chains scored third place with force ranged from 239.4 to 223.2 grams and finally Ultimate power chains with force ranged from 203.2 to 196.6 grams. The more force delivered initially by elastic types, the higher force decay will be obtained ${ }^{13}$.

In previous study, the loss in the force amount was greater in wet than dry, so saliva has an effect on the increase in force decay ${ }^{14}$. There was also report for higher force decay in the first 24 hours $^{12,15}$. To understand the force decay, it will be easy to assess the correct amount of force needed to move the teeth, as Quinn and Yoshikawa estimated a force of 100 to 200 grams was the best and efficient for canine retraction ${ }^{16}$. Force of 150 to 250 grams needed for upper canines bodily movement, while the lower canines may need between 100 to 200 grams and lesser force needed for premolars movement ${ }^{17}$. 50 to $85 \%$ decrease in force occur after 4 weeks, with a great amount in the first day, with assortments that all authors indicate that force dropped in the first hours by 40 to $50 \%{ }^{3}$.

Another study concluded that permanent 
deformation occur by higher value during first week and wasn't significant after this period ${ }^{18}$. In the present study, the maximum percentage of force decay occurred after 24 hours was 26.7 $\%$ and that contradicts with the work of other study ${ }^{19}$.

\section{Conclusion}

1- All the four types of power chain showed different values of force decay after immersion in artificial saliva.

2- There was a variability of force value among the modules of the same power chain strand, meaning that a strand of six modules from certain power chain scored a different value of force if compared to another strand from the same type of the power chain.

3- In the beginning of the test, Morrelli chain showed higher force value followed by Dentsply, followed by Ultra-Chain and finally come Ultimate Power.

4- After 3 weeks of immersing in artificial saliva, Morrelli was found with greater percentage of force decay followed by Ultimate Power, followed by Dentsply and finally come Ultra-chain.

5- For clinical application in orthodontic treatment, if initial force needed that range from 100 to 200 grams, the choice will be Ultimate power chain, on the other hand if more force needed from 200 to 300 grams or more, the choice will be Ultra-chain then Dentsply and Morelli respectively.

\section{References}

1-Wahab SW, Bister D, Sherriff M. An investigation into UV light exposure as an experimental model for artificial aging on tensile strength and force delivery of elastomeric chain. Eur J Orthod. .2013; 36:47-54.

2-Halimi A, Azeroual MF, Eddimani L, NatiqA,
Bakri Y, Zaoui, F. Cytotoxicity of elastomeric power chains in artificial saliva: An in vitro study. Int Orthod. .2015; 13:16-25.

3-Halimi A, Benyahia H, Doukkali A, Azeroual MF, Zaoui F. A systematic review of force decay in orthodontic elastomeric power chains. Int Orthod. 2012; 10:223-240.

4-Lu TC, Wang WN, Tarng TH, Chen JW. Force decay of elastomeric chain-a serial study Part II. Am J Orthod Dentofac Orthop. $1993 ; 104: 373-377$.

5-Buchmann N, Senn C, Ball J, Brauchli L. Influence of initial strain on the force decay of currently available elastic chains over time. Angle Orthod. 2012; 82:529-535.

6-Kim KH, Chung $\mathrm{CH}$, Choy K, Lee SJ, Vanarsdall RL. Effects of prestretching on force degradation of synthetic elastomeric chains. Am J Orthod Dentofacial Orthop. 2005; 128:477-482.

7-Halimi A, Azeroual MF, Doukkali A, Mabrouk $\mathrm{KE}$, Zaoui F. Elastomeric chain force decay in artificial saliva: An in vitro study. Int Orthod. 2013; 11:60-70.

8-Pithon MM, Mendes JL, da Silva CA, dos Santos RL, Coqueiro R. Force decay of latex and non-latex intermaxillary elastics: a clinical study. Eur J of Orthod. 2015; 38:39-43.

9-Lee TH, Huang TK, Lin SY, Chen LK, Chou MY, Huang HH. Corrosion resistance of different nickel-titanium archwires in acidic fluoride-containing artificial saliva. Angle Orthod. 2010; 80:547-553.

10-Kanuru RK, Azaneen M, Narayana V, Kolasan B, Indukuri RR, Babu FP. Comparison of canine retraction by in vivo method using four brands of elastomeric power chain. J of Int Soc of Prevent Communit Dent. 2014; 4:32-37.

11-de Aguiar AM, de Aguiar AM, de 
Araujo Gurgel J, Vercelino CRMP, Filho EMM, Bandeca MC, de jesus Tavarez RR. The prestretching effect on the force decay of orthodontic elastic chain. J Contemp Dent Pract. 2014; 15:456-460.

12-Balhoff DA, Shuldberg M, Hagan JL, Ballard RW, Armbruster PC. Force decay of elastomeric chains-amechanical design and product comparison study. J of Orthod. 2011; 38:40-47.

13-Mirhashemi AH, Saffarshahroudi A, Sodgar A, Atai M. Force degradation pattern of sex different orthodontic elastomeric chains. J of Dent. 2012; 9:204-215.

14-Lopez N, Vicente A, Bravo LA, Calvo JL, Canteras M. In vitro study of force decay of latex and non-latex orthodontic elastics. Eur J Orthod. 2011; 34:202-207.

15-Omidkhoda M, Rashed R, Khodarahmi $N$. Evaluation of the effects of three different mouthwashes on the force decay of orthodontic chains. Dent Res J.2015; 12:348-352.

16-Quinn RS, Yoshikawa DK. A reassessment of force magnitude in orthodontics. Am J Orthod. 1985; 88:252-260.

17-Reitan K. Some factors determining the evaluation of forces in orthodontics. Am J Orthod. 1957 43:32-45.

18-Yagura D, Baggio PE, Carreiro LS, Takahashi R. Deformation of elastomeric chains related to the amount and time of stretching. Dent Press J Orthod. 2013; 18:136-142.

19-Aminian A, Nakhaei S, Agahi RH, Rezaeizade M, Aliabadi HM, Heidarpour M. Evaluation of the effect of different stretching patterns on force decay and tensile properties of elastomeric ligatures. Dent Res J. 2015; 12:589-595.

\section{Illustration legends.}

Table (1): comparison between the two studied groups according to force (grams) of elastic samples.

Graph (1): The behavior of force decay of the chain samples different time intervals.

Fig (1): power chain samples.

Fig (2): stone blocks with steel pins.

Fig (3): force calculation after 1 minute. 